\title{
A review of oesophageal manometry testing in a district general hospital
}

\author{
K Ragunath, J G Williams
}

Postgrad Med J 2002;78:34-36

See end of article for authors' affiliations

\section{.................. \\ Correspondence to:}

Dr K Ragunath,

Gastrointestinal Unit,

University Hospital Áintree,

Lower Lane, Liverpool

L9 7AL, UK;

ragunath@doctors.org.uk

Submitted

16 February 2001

Accepted 24 July 2001

\begin{abstract}
Although several modalities are available to investigate oesophageal motility disorders, manometry is the gold standard. The procedure is increasingly available in district general hospitals but the clinical utility of this investigation in this setting remains unclear. The aim in this study was to evaluate the use and outcome of oesophageal manometry in a district general hospital. Data on 100 consecutive oesophageal manometry procedures were analysed, taking into account the referral pattern, indications, and results. The indications were gastro-oesophageal reflux disease (preoperative assessment before fundoplication) (58), dysphagia (28), chest pain (12), and epigastric pain (2). Diagnoses were made using predefined standard criteria and were as follows: normal (41), non-specific motility disorder (NSMD) (38), achalasia (15), diffuse oesophageal spasm (4), and scleroderma (2). Of the 58 patients who had undergone manometry as a preoperative assessment of oesophageal motility, 27 $(47 \%)$ were abnormal. Twenty five $(43 \%)$ had NSMD and two $(3 \%)$ had achalasia. Forty eight of these preoperative cases were combined with 24 hour $\mathrm{pH}$ recording, which confirmed acid reflux in 35 $(73 \%)$. The experience reported here reflects the published evidence that the use of manometry is changing. It is now more commonly used for assessment before antireflux surgery and for dysphagia, and the use in the assessment of chest pain is declining. The findings confirm the importance of eliminating achalasia before inappropriate antireflux surgery.
\end{abstract}

\section{PATIENTS AND METHODS}

The records of 100 consecutive patients referred for oesophageal manometric studies to our department over a 14 month period from September 1998 to December 1999 were analysed, taking into account the referral pattern, indications, and results. Manometry was performed using the Synectics Polygraph with polygram software (Synectics Medical, Enfield, UK) and Gaeltec catheters (Gaeltec Ltd, Isle of Skye, Scotland, UK), with three solid state transducers placed $5 \mathrm{~cm}$ apart. Normal values for oesophageal function are not available using this system. Data derived from a water perfused system ${ }^{2} 3$ are shown in box 1. Manometric diagnoses were made using predefined criteria ${ }^{4}$ as shown in box 2 . All patients gave written informed consent before the procedure. After a 12 hour fast the calibrated catheter was passed transnasally with the patient semirecumbent. The study was carried out in the same position throughout, using the same technique in all patients. The catheter was initially positioned so that all three transducers were recording from the stomach. The catheter was then withdrawn in a stepwise fashion in 1 $\mathrm{cm}$ steps (station pull through technique) and the lower oesophageal sphincter (LOS) pressure was measured after identification of the respiratory inversion point. Wet swallows were performed ( $5 \mathrm{ml}$ room temperature water) when each of the three transducers were in the high pressure zone of the

\section{Box 1: Normal values used to categorise manometric} features $^{2}$

\section{Lower oesophageal sphincter station analysis (wet} swallows):

- Resting pressure: 16.6-35.4 mm Hg

Oesophageal body motility analysis (wet swallows):

- Peristaltic performance as \% of normal swallows: $>90$.

- Mean amplitude (distal): $64-154 \mathrm{~mm} \mathrm{Hg}$.

- Mean amplitude (proximal): $33-91 \mathrm{~mm} \mathrm{Hg}$

- Mean duration (distal): 2.9-5.1 sec.

- Mean duration (proximal): 2.0-3.6 sec.

LOS, to measure average LOS pressure and relaxation. The catheter was withdrawn further with the distal transducer 5 $\mathrm{cm}$ above the LOS and 10 wet swallows were recorded at 30 second intervals in the oesophageal body. The catheter was then withdrawn in a stepwise fashion until the upper oesophageal sphincter was identified, and relaxation confirmed on dry swallow. All data were stored on computer and analysed before reporting.

\section{RESULTS}

There were 46 male and 54 female patients with an age range of 15-81 years, mean 52.8 years. The referrals were from six different hospitals in south Wales and from surgeons (51 patients), physicians (47 patients), and paediatricians (two patients). The indications and diagnosis are summarised in table 1. Forty eight of 58 cases with suspected gastrooesophageal reflux disease (GORD) studied preoperatively

Abbreviations: GORD, gastro-oesophageal reflux disease; LOS, lower oesophageal sphincter; NCCP, non-cardiac chest pain; NSMD, non-specific motility disorder 
Table 1 Indications and diagnosis in patients studied

\begin{tabular}{llllll}
\hline & \multicolumn{2}{l}{ Diagnosis } & & & \\
\cline { 2 - 6 } Indication & Normal & Achalasia & NSMD & DOS & Scleroderma \\
\hline Dysphagia $(n=28)$ & 3 & 13 & 6 & 4 & 2 \\
GORD $(n=58)$ & 29 & 2 & 27 & 0 & 0 \\
NCCP $(n=12)$ & 7 & 0 & 5 & 0 & 0 \\
Epigastric pain $(n=2)$ & 2 & 0 & 0 & 0 & 0 \\
Total 100 & 41 & 15 & 38 & 4 & 2 \\
\hline
\end{tabular}

GORD, gastro-oesophageal reflux disease; NCCP, non-cardiac chest pain; NSMD, non-specific oesophageal motility disorder; DOS, diffuse oesophageal spasm.

also underwent 24 hour pH recording, which confirmed acid reflux in $35(73 \%)$. Ten patients with non-cardiac chest pain (NCCP) had manometry and 24 hour pH study combined, out of which eight (80\%) had reflux and the remaining two (20\%) were normal. Two patients with epigastric pain had normal manometric findings and were shown to have gallstones on ultrasound.

\section{DISCUSSION}

There is little doubt as to the usefulness of manometry in diagnosing oesophageal motility disorders. Because of the low

Box 2: Manometric classification of oesophageal motility abnormalities (adapted from Castell and Castell ${ }^{4}$ )

Achalasia

- Absent distal peristalsis. *

- Raised resting LOS pressure (>45 mm Hg). $\dagger$

- Incomplete LOS relaxation (residual pressure $>8 \mathrm{~mm} \mathrm{Hg}$ ). $\dagger$

- Raised baseline oesophageal pressure. $†$

Diffuse oesophageal spasm

- Simultaneous contractions (>20\% wet swallows). *

- Intermittent normal peristalsis. *

- Repetitive contraction (>3 peaks). $\dagger$

- Prolonged duration contractions (>6 sec). $\dagger$

- Retrograde contractions. $\dagger$

- Isolated incomplete LOS relaxation (>8 mm Hg). $\dagger$

Nutcracker oesophagus

- Increased distal peristaltic amplitude (>180 mm Hg). *

- Increased distal peristaltic duration $(>6 \mathrm{sec}) . \dagger$

Hypertensive LOS

- Resting LOS pressure $>45 \mathrm{~mm} \mathrm{Hg}$. *

- Incomplete LOS relaxation (residual pressure $>8 \mathrm{~mm} \mathrm{Hg}$ ). $\dagger$

Hypocontracting oesophagus (may be secondary to GORD)

- Increased non-transmitted peristalsis (>30\%). $\neq$

- Low distal peristaltic amplitude $(<30 \mathrm{~mm} \mathrm{Hg})$. $\neq$

- Hypotensive LOS (resting LOS pressure $<10 \mathrm{~mm} \mathrm{Hg}$ ).

Scleroderma oesophagus

- Low LOS pressure.*

- Weak or absent distal peristalsis. *

- Normal upper oesophagus and upper oesophageal sphincter. *

Non-specific oesophageal motility disorder

- Intermittent peristalsis with frequent non-transmitted contractions. ‡

- Triple peaked contractions. $\neq$

- Retrograde contractions. $\neq$

- Low amplitude contractions $(<30 \mathrm{~mm} \mathrm{Hg}) . \ddagger$

- Isolated, incomplete LOS relaxation (residual pressure >8 $\mathrm{mm} \mathrm{Hg})$. $\neq$

*Required for diagnosis; †may be seen, not required; feither or all may be seen. prevalence of these disorders, manometry has tended to remain in tertiary gastroenterology units even in developed countries. The American Gastroenterology Association ${ }^{5}$ and the British Society of Gastroenterology $y^{6}$ have published guidelines (box 3), which define the indications and clinical use of manometry, and the technique is becoming more widely available. In this study we have reviewed the clinical utility of oesophageal motility testing in a district general hospital setting. Our results are comparable to the North American study by Alrakawi and Clouse who reviewed 1162 patients seen over a 10 year period.?

The most common indication for manometry in our study was assessment of oesophageal motility in patients with GORD before an antireflux procedure. All these patients were diagnosed to have GORD based on clinical, endoscopic, and 24 hour $\mathrm{pH}$ studies. There have been conflicting reports in the literature on the value of preoperative motility testing. ${ }^{8-10}$ In spite of these controversies, some centres are now advocating tailoring the antireflux procedure to the preoperative motility pattern. ${ }^{11}$ This is based on the knowledge that distal oesophageal body motility can be affected by GORD, ${ }^{12}$ and more severe and progressive reflux seems to result in greater dysfunction of oesophageal motility with an end result of hypoperistalsis. ${ }^{13}$ It is therefore thought justifiable to evaluate the propulsive force of the oesophageal body by manometry to determine if it has sufficient power to propel a bolus of food through a newly constructed LOS.

In our study, $43 \%$ of patients who underwent preoperative motility testing were diagnosed to have non-specific oesophageal motility disorder (NSMD) and this did not alter the treatment decision to operate. A diagnosis of achalasia was made in $3 \%$ of the patients, which radically altered the management. Although these patients gave a history suggestive of GORD. There have been reports of patients suffering from GORD subsequently developing achalasia. ${ }^{14}{ }^{15} \mathrm{~A}$ few of these patients have had mild and intermittent dysphagia accompanying reflux symptoms. The exact pathophysiology of this association is not clearly understood. It has been suggested that the autonomic damage eventually leading to achalasia may in its initial phases cause gastro-oesophageal reflux. Although this is uncommon, it is clearly important to exclude achalasia especially in patients with dysphagic symptoms before subjecting them to surgery.

Box 3: British Society of Gastroenterology guidelines on the indications for oesophageal manometry

- To diagnose and categorise suspected oesophageal motility disorders in patients with dysphagia or chest pain in whom other investigations are negative or equivocal.

- For the accurate placement of $\mathrm{pH}$ electrodes for 24 hour $\mathrm{pH}$ monitoring.

- Before surgical treatment for gastro-oesophageal reflux.

- Should not be used to diagnose reflux, nor as first line investigation in patients with dysphagia or chest pain. 
Learning points

- Clinical indications for oesophageal manometry are changing.

- It is more commonly used in the preoperative assessment of motility before antireflux surgery.

- Its use in preoperative assessment is controversial, nevertheless, it is justifiable to exclude significant dysmotility.

- It is of value in evaluating dysphagia when obstructive causes are excluded.

- It is of limited value in the assessment of non-cardiac chest pain.

Non-cardiac chest pain was an indication for motility testing in only $12 \%$ of our patients, and $58 \%$ was normal. The remainder had NSMD. It is difficult to know how to interpret these results, as patients are often asymptomatic during the procedure. Provocative studies and ambulatory monitoring can improve the yield, but we do not offer these techniques. However, a recent study suggests that findings consistent with diffuse oesophageal spasm on stationary manometry correlates poorly with abnormal motility associated with pain events during ambulatory pressure monitoring. ${ }^{16}$ Reflux is the most likely abnormality related to pain in patients with unexplained chest pain. ${ }^{17}$ In our study the majority (80\%) of patients with NCCP had confirmed reflux on 24 hour $\mathrm{pH}$ study, and this is likely to be a more rewarding investigation in the evaluation of these patients.

In conclusion, our experience reflects the published evidence that the use of manometry is changing. ${ }^{7}$ It is now more commonly used for assessment before antireflux surgery and for dysphagia, and the use in the assessment of chest pain is declining. It has poor clinical value in NCCP other than to reassure the patient. Our findings confirm the importance of eliminating achalasia before inappropriate antireflux surgery.

\section{ACKNOWLEDGMENTS}

We would like to thank Ms Pauline Williams (gastroenterology secretary) and Ms Ruth Saele (gastroenterology specialist nurse) for their help in data collection. Janssen Pharmaceuticals generously provided a grant to set up the oesophageal function service.

\section{Authors' affiliations}

K Ragunath, J G Williams, Department of Gastroenterology, Neath General Hospital, Neath, South Wales, UK

\section{REFERENCES}

1 Code CF, Creamer B, Schegel JF, et al. An atlas of esophageal motility in health and disease. Springfield, IL: Charles C Thomas, 1958.

2 Castell J, Gideon RM, Castell DO. In: Schuster MM, ed. Atlas of gastrointestinal motility in health and disease. Baltimore: Williams and Wilkins, 1993: 134-57

3 Richter JE, Wu WC, Johns DN, et al. Esophageal manometry in 95 healthy adult volunteers: variability of pressures with age and frequency of "abnormal" contractions. Dig Dis Sci 1987;32:583-92.

4 Castell DO, Castell JA. Esophageal motility testing. 2nd Ed. Norwalk: Appleton and Lange, 1994.

5 Kharilas PJ, Clouse RE, Hogan WJ. American Gastroenterological Association technical review on the clinical use of esophageal manometry. Gastroenterology 1994;107:1865-84.

6 Guidelines for oesophageal manometry and $\mathrm{pH}$ monitoring. BSG guidelines in gastroenterology. London: British Society of Gastroenterology, September 1996.

7 Alrakawi A, Clouse RE. The changing use of esophageal manometry in clinical practice. Am J Gastroenterol 1998;12:2359-62.

8 Perdikis G, Lund RJ, Hinder RA, et al. Esophageal manometry and 24-hour $\mathrm{pH}$ testing in the management of gastroesophageal reflux patients. Am J Surg 1997;6:634-7.

9 Mughal MM, Bancewicz J, Marples M. Oesophageal manometry and $\mathrm{pH}$ recording does not predict the bad results of Nissen fundoplication. Br J Surg 1990;77:43-5.

10 Oritz Escandell A, Martinez de Haro LF, Parrilla Paricio P, et al. Surgery improves defective oesophageal peristalsis in patients with gastro-oesophageal reflux. Br J Surg 1991;78:1095-7.

11 Kaver WK, Peters JH, De Meester TR, et al. A tailored approach to antireflux surgery. J Thorac Cardiovasc Surg 1995;110:141-7.

12 Kharilas PJ, Dodds W, Hogan WJ, et al. Esophageal peristaltic dysfunction in peptic esophagitis. Gastroenterology 1986;91:897-904

13 Mason RJ, Bremner CC. Motility differences between long-segment and short-segment Barrett's esophagus. Am J Surg 1993;165:686-9.

14 Smart HL, Mayberry JF, Atkinson M. Achalasia following gastro-oesophageal reflux. J R Soc Med 1986;79:71-3.

15 Robson K, Rosenberg S, Lembo T. GERD progressing to diffuse esophageal spasm and then to achalasia. Dig Dis Sci 2000;45:1 10-3.

16 Barham C, Gotley D, Fowler A, et al. Diffuse oesophageal spasm: diagnosis by ambulatory 24-hour manometry. Gut 1997;41:151-5.

17 Katzka DA, Castell DO. Esophageal manometry and modern medicine. Dig Dis 1998;16:189-91. 